\section{Abscisic Acid Accumulation in Relation to Drought Tolerance in Kentucky Bluegrass}

\author{
Zhaolong Wang, ${ }^{1}$ Bingru Huang, ${ }^{2}$ Stacy A. Bonos, and \\ William A. Meyer \\ Department of Plant Biologyand Pathology, Rutgers University, New Brunswick, \\ NJ 08901
}

Additional index words. Poa pratensis, electrolyte leakage, photosynthetic rate, relative water content, stomatal conductance, water stress

\begin{abstract}
Drought is a major factor limiting plant growth, which has been associated with the accumulation of absicsic acid (ABA) in various species. The objective of the study was to determine the relationship between $\mathrm{ABA}$ accumulation and drought tolerance for kentucky bluegrass (Poa pratensis L.) during short-term drought stress. Eight kentucky bluegrass cultivars ('Midnight', 'A82-204', 'RSP', ‘Alpine', 'Moonlight', 'Brilliant', 'Washington', and 'Baruzo') were subjected to drought stress in a growth chamber. Water relations, gas exchange rate, and $\mathrm{ABA}$ content of leaves were determined at various times during drought stress. Turf quality decreased with drought duration for all eight cultivars. Leaf ABA content increased linearly with drought stress within 11 days of treatment; the rate of the increase was negatively related to the rate of turf quality decline. The rate of ABA accumulation during drought stress was positively correlated with the rates of decrease in turf quality $\left(r^{2}=0.6346\right)$, increase in electrolyte leakage $\left(r^{2}=0.7128\right)$, and decrease in relative water content $\left(r^{2}=0.5913\right)$. There were highly significant negative correlations between ABA content and leaf water potential $\left(r^{2}=0.9074\right)$, stomatal conductance $\left(r^{2}=\right.$ $0.6088)$, transpiration rate $\left(r^{2}=0.6581\right)$, net photosynthesis rate $\left(r^{2}=0.6956\right)$, and a positive correlation between ABA content and electrolyte leakage $\left(r^{2}=0.7287\right)$. The results indicate that drought tolerance is negatively related to $\mathrm{ABA}$ accumulation during shortterm drought stress. ABA accumulation in response to drought stress could be used as a metabolic factor to select for drought tolerance in kentucky bluegrass.
\end{abstract}

Drought is one of the most important environmental factors limiting growth of turfgrasses and can cause severe decline in turf quality, particularly for cool-season grasses (Aronson et al., 1987; Beard, 1973; Huang et al., 1998). The ability of plant tolerance to drought stress is associated with the maintenance of high leaf water potential, stomatal conductance, transpiration, and photosynthesis, but low levels of electrolyte leakage (an indicator of cell membrane stability) during drought stress (Huang and Gao, 1999; Jiang and Huang, 2001; Lehman et al., 1993; Qian and Fry, 1997). These physiological parameters have been widely used as physiological indicators for the selection of drought-tolerant plant materials (Blum, 1989; Bonos and Murphy, 1999; Huang et al., 1998; Qian and Fry, 1997).

Abscisic acid (ABA) is an essential constituent of higher plants, which often increases in quantity under stressful conditions, particularly drought stress. Its importance as a metabolic factor in the regulation of plant tolerance to stresses has received great attention in recent years (Cao et al., 2000; Quarrie, 1993). ABA initiates a signal cascade in guard cells that alters the membrane transport of several ions, and as a result guard cells lose their turgor

Received for publication 25 Sept. 2002. Accepted for publication 28 Apr. 2003.

${ }^{1}$ Postdoctoral research associate.

${ }^{2}$ Associate professor; to whom reprint requests should be addressed; e-mail huang@aesop.rutgers.edu. and stomata close. This results in changes of stomatal conductance, transpiration rate, and photosynthesis (Bohnert et al., 1995; Bray, 1993; Ludewig et al., 1988; Zhang et al., 1995). ABA content increases with drought stress in various plant species, but the extent and rate of ABA accumulation vary with species and cultivars differing in drought tolerance (Conti et al., 1994; Pekic and Quarrie, 1987; Pekic et al., 1995; Tuberosa et al., 1992). Several studies in annual crops found that drought-tolerant cultivars (in terms of the least reduction in grain yield under drought stress) tended to accumulate less ABA in wilting leaves than drought-susceptible ones, and suggest that low leaf ABA accumulation could be used as a selection criterion to improve drought tolerance in breeding programs [wheat (Triticum aestivum L.): Innes et al., 1984; Quarrie, 1989; sorghum (Sorghum bicolor L.): Durley et al., 1983; maize (Zea mays L.): Landi et al., 2001]. Other studies suggest that high ABA accumulation is positively related to drought tolerance (Larque-Saavedra and Wain, 1976). A linkage between ABA accumulation and physiological responses may exist under drought stress. While the role of ABA in the regulation of drought resistance has been reported in other species, mainly annual crops, how ABA accumulation is related to water relation, gas exchange rate, and cell membrane stability for perennial turfgrasses exposed to drought stress has not been determined.A study of the relationship between ABA accumulation and changes in various physiological stress indicators may reveal a pattern of plant response in ABA accumulation in relation to drought tolerance of turfgrass. Evaluation of ABA accumulation could be used as a powerful tool for genetic improvement of drought tolerance in turfgrass.

The objectives of this study were to investigate the relationship between leaf ABA accumulation and several commonly used physiological indicators for plants exposed to short-term drought stress and to determine the relationship between ABA accumulation and drought tolerance for kentucky bluegrass cultivars.

\section{Materials and Methods}

Sod pieces $(15 \mathrm{~cm}$ in diameter and $2 \mathrm{~cm}$ deep) of eight kentucky bluegrass cultivars ('Midnight', 'A82-204', 'RSP', 'Alpine', 'Moonlight', 'Brilliant', 'Washington', and 'Baruzo') were collected from 2-year-old field plots at the Rutgers Plant Biology and Pathology Research Farm, Adelphia, N.J. Sod pieces were washed free of soil before planting in 20 -cm-diameter $\times 40$-cm-deep pots filled with a mixture of 1 sand : 3 top soil (fine, montmorillonitic, mesic, aquic arquidolls) (by volume). Plants were grown in a greenhouse for $60 \mathrm{~d}$ and then transferred to growth chambers with temperatures of $22{ }^{\circ} \mathrm{C}$ day $/ 18^{\circ} \mathrm{C}$ night, 14 -h photoperiod, and a photosynthetic photon flux density $(P P F D)$ of $600 \mu \mathrm{mol} \cdot \mathrm{m}^{-2} \cdot \mathrm{s}^{-1}$. Grasses were maintained in growth chambers for $15 \mathrm{~d}$ before drought treatment was imposed. Slowrelease fertilizer containing $17 \mathrm{~N}-6 \mathrm{P}-10 \mathrm{~K}$ was topdressed twice during the 60-d growing period before dry-down to provide total $\mathrm{N}$ at $17 \mathrm{~g} \cdot \mathrm{m}^{-2}$. Turf was hand-clipped twice weekly at $\approx 6$-cm height before drought treatment and not clipped during the treatment period.

Plants were watered until drainage occurred from the bottom of each pot on alternate days before drought treatments were initiated. During drought stress, irrigation was withheld, allowing soil to dry for $25 \mathrm{~d}$. Grasses were not clipped during the dry-down period. Volumetric soil water content in 0-20 cm soil layer was monitored to determine soil dryness during drought stress by time domain reflectometry (TDR; Soil Moisture Equipment Corp., Santa Barbara, Calif.). The TDR rods were inserted vertically in the soil. The field capacity of the sand and topsoil mix was $28 \% \pm 0.5 \%$ (mean of eight replications \pm standard error), which was measured in eight pots with TDR when drainage ceased following watering the soil to saturation. Soil water content dropped to $17.8 \% \pm 0.43 \%$ at $12 \mathrm{~d}$, and down to $5.2 \% \pm$ $0.27 \%$ at $25 \mathrm{~d}$.

Turf quality and physiological parameters were evaluated on alternate days during the 11 -d dry-down period. Turf quality was visually rated based on leaf color, shoot density, and uniformity of color and density on a 0 to 9 scale, where $0=$ worst quality, and $9=$ best quality. All physiological measurements were made on six fully expanded leaves (blades fully exposed from the sheath) from different plants in each pot. Leaf net photosynthetic rate $(\mathrm{Pn})$, stomatal conductance $\left(g_{\mathrm{s}}\right)$, and transpira- 
tion rate $(\mathrm{Tr})$ were measured with a portable gas exchange system (LI-6400; Li-COR Inc., Lincoln, Nebr.) at a PPFD of $800 \mu \mathrm{mol} \cdot \mathrm{m}^{-2} \cdot \mathrm{s}^{-1}$ and a chamber temperature of $22^{\circ} \mathrm{C}$ from 1000 to $1400 \mathrm{HR}$ at each measurement time. Leaf relative water content (RWC) was calculated as (fresh weight - dry weight)/(turgid weight - dry weight) $\times 100$.

The turgid weight of leaves was measured after soaking leaves in water overnight at 20 ${ }^{\circ} \mathrm{C}$. Leaf water potential was measured with a thermocouple psychrometer(Tru Psi; Decagon Devices, Pullman, Wash.). Cell membrane stability was estimated by measuring electrolyte leakage (EL). Samples of 0.1-g leaves were rinsed and immersed in $20 \mathrm{~mL}$ of deionized water. The conductivity of the solution $\left(\mathrm{C}_{\text {initial }}\right)$ was measured after the leaves were shaken for $24 \mathrm{~h}$. Leaves then were killed by autoclaving at $140{ }^{\circ} \mathrm{C}$ for $20 \mathrm{~min}$. The conductivity of killed tissues $\left(\mathrm{C}_{\max }\right)$ was measured after samples were cooled down to the room temperature. Relative EL was calculated as the percentage of $\mathrm{C}_{\text {initial }}$ over $\mathrm{C}_{\max }$.

Leaves were sampled on the same days as for the other measurements described above for abscisic acid (ABA) analysis. Extraction and analysis of ABA followed the methods described in Alves and Setter (2000). Five hundred milligrams of fresh leaves per sample were extracted in $80 \%(\mathrm{v} / \mathrm{v})$ methanol [with $1 \%(\mathrm{v} / \mathrm{v})$ glacial acetic acid and $10 \mathrm{mg} \cdot \mathrm{L}^{-1}$ butylated hydroxytoluene, sample: extraction $=1: 10]$. Thirty Becquerels of ${ }^{3} \mathrm{H}-\mathrm{ABA}$ was added to each sample to monitor loss of ABA during the purification. A $200-\mu \mathrm{L}$ aliquot of each extract was dried in vacuum at $<24{ }^{\circ} \mathrm{C}$, then redissolved in $100 \mu \mathrm{L}$ of Solvent I [ $20 \%$ $(\mathrm{v} / \mathrm{v})$ methonal $+1 \%(\mathrm{v} / \mathrm{v})$ glacial acetic acid]. ABA was separated with reverse-phase chromatography on columns packed with $25 \mathrm{mg}$ of $40-\mu \mathrm{m}$ diameter $\mathrm{C}_{18}$-silica material
(SPE-96; Supelco, Bellefonte, Pa.). Solvents were eluted in a vacuum manifold $(\mathrm{psi}<5)$. Columns were pre-equilibrated with Solvent $\mathrm{I}$; then samples were loaded in $100 \mu \mathrm{L}$, and contaminants were eluted with $400 \mu \mathrm{L}$ of Solvent I and for radioactive count. ABA was eluted with $200 \mu \mathrm{L}$ of Solvent II [55\% (v/v) methanol $+1 \%(\mathrm{v} / \mathrm{v})$ glacial acetic acid]. Radiolabelled tracer ABA indicated greater than $90 \%$ recovery of $\mathrm{ABA}$ with this procedure. ABA fractions were dried in vacuum at $<24$ ${ }^{\circ} \mathrm{C}$, and then resuspended in $200 \mu \mathrm{L}$ buffer (pH. 7.5) containing $150 \mathrm{~mm} \mathrm{NaCl}$ and 10 $\mathrm{mm}$ Tris- $\mathrm{HCl})$. ABA was assayed by indirect enzyme linked immunosorbant assay (ELISA) as described by Alves and Setter (2000). High specific (+)-ABA monoclonal antibody (PDM 09347/0096; Agdia Inc., Elkhart, Ind.) was used for ELISA.AfterELISA processes, absorbance at $405 \mathrm{~nm}$ was read with a plate reader (model EL800; Bio-Tek Instruments Inc., Winooski, Vt.). (+) ABA content was calculated based on (+)ABA calibration standards and a logarithm transformation of data.

The experiment was a completely randomized design with four replications for each treatment and cultivar. Each measurement was taken in four replicated pots. Treatment effects were determined by analysis of variance according to the general linear model (GLM) procedure of the Statistical Analysis System (SAS Institute, Cary, N.C.). The pattern of ABA accumulation and turf quality decline in each cultivar and the relationships between ABA content and physiological parameters were determined using Pearson's correlation analysis. The significance of the correlation coefficients was tested at a probability level of 0.01 and 0.001 . The differences in the rates of changing turf quality over time(slopes) between cultivars were tested using the homogeneity-of-slopes model in the GLM procedure of SAS.

Table 1 . Turf quality decline during 25 -d dry-down in eight kentucky bluegrass cultivars.

\begin{tabular}{lccc}
\hline Cultivar & Equation $^{\mathrm{z}}(\mathrm{df}=22)$ & Coefficient $\left(R^{2}\right)$ & Slope difference \\
\hline RSP & $\mathrm{Y}=-0.2458 \mathrm{X}+8.592$ & $0.9753^{* * * *}$ & $\mathrm{~A}$ \\
Moonlight & $\mathrm{Y}=-0.2418 \mathrm{X}+8.5255$ & $0.9496^{* * * *}$ & $\mathrm{~A}$ \\
Brilliant & $\mathrm{Y}=-0.214 \mathrm{X}+8.2951$ & $0.9614^{* * *}$ & $\mathrm{AB}$ \\
Baruzo & $\mathrm{Y}=-0.1552 \mathrm{X}+8.3843$ & $0.9366^{* * *}$ & $\mathrm{~B}$ \\
Alpine & $\mathrm{Y}=-0.1692 \mathrm{X}+8.4477$ & $0.9290^{* * *}$ & $\mathrm{~B}$ \\
Washington & $\mathrm{Y}=-0.1213 \mathrm{X}+6.8484$ & $0.9686^{* * *}$ & $\mathrm{BC}$ \\
A82-204 & $\mathrm{Y}=-0.1429 \mathrm{X}+8.5383$ & $0.9871^{* * *}$ & $\mathrm{BC}$ \\
Midnight & $\mathrm{Y}=-0.0747 \mathrm{X}+8.8718$ & $0.8649^{* * *}$ & $\mathrm{C}$ \\
\hline
\end{tabular}

${ }^{2} \mathrm{Y}=$ turf quality; $\mathrm{X}=$ days of drought stress.

${ }^{* * * *}$ Significant at $P=0.001$. Slopes in the equations that were not significantly different at $P=0.05$ were marked with the same alphabetical letters.

Table 2. The linear relationship of ABA accumulation and drought duration (11 d) for eight kentucky bluegrass cultivars.

\begin{tabular}{llcc}
\hline Cultivar & Equation $^{2}(\mathrm{df}=22)$ & Coefficient $\left(r^{2}\right)$ & Slope difference \\
\hline RSP & $\mathrm{Y}=37.47 \mathrm{X}-73.08$ & $0.0 .8996^{* *}$ & $\mathrm{~A}$ \\
Moonlight & $\mathrm{Y}=33.05 \mathrm{X}-51.26$ & $0.8589^{* *}$ & $\mathrm{~A}$ \\
Brilliant & $\mathrm{Y}=33.46 \mathrm{X}-59.78$ & $0.8408^{* *}$ & $\mathrm{~A}$ \\
Baruzo & $\mathrm{Y}=27.72 \mathrm{X}-55.74$ & $0.8678^{* *}$ & $\mathrm{~B}$ \\
Alpine & $\mathrm{Y}=22.03 \mathrm{X}-27.55$ & $0.7190^{* * *}$ & $\mathrm{~B}$ \\
Washington & $\mathrm{Y}=16.99 \mathrm{X}-17.38$ & $0.7307^{* *}$ & $\mathrm{C}$ \\
A82-204 & $\mathrm{Y}=10.93 \mathrm{X}-12.43$ & $0.8146^{* *}$ & $\mathrm{C}$ \\
Midnight & $\mathrm{Y}=18.79 \mathrm{X}-45.54$ & $0.8473^{* *}$ & $\mathrm{BC}$
\end{tabular}

${ }^{2} \mathrm{Y}=$ ABA quality; $\mathrm{X}=$ days of drought stress.

${ }^{*}$ Significant at $P=0.001$. Slopes in the equations that were not significantly different at $P=0.05$ were marked with the same alphabetical letters.

\section{Results and Discussion}

Turf quality declined linearly during the first $20 \mathrm{~d}$ of drought initiation for all eight cultivars. The rate of turf quality decline was greatest for 'RSP' and 'Moonlight'; lowest for 'Midnight', 'A82-204', and 'Washington'; and intermediate for 'Brilliant', 'Baruzo', and 'Alpine' (Table 1). Turf quality reflects the overall performance of turfgrass. The current study was conducted in pots with limited soil volume and uniform soil moisture content from the surface to the bottom of the pot. Genotypic variations in turf performance may be mainly contributed by drought tolerance. Our previous study (Wang and Huang, 2003) compared drought tolerance among 'Midnight', 'A82-204', 'Brilliant', and 'RSP' and found the same ranking of drought tolerance for these cultivars as in this study. In a previous study conducted in the field study, however, 'RSP' performed well under summer stress (combined heat and drought stress). Under field conditions, 'RSP' had deep rooting, which may be able to avoid drought stress by taking up water from deeper soil profile (Bonos and Murphy, 1999).

Leaf ABA content did not change and was maintained at the control level (averaged 12.4 $\mathrm{pmol} \cdot \mathrm{g}^{-1}$ fresh weight for eight cultivars) within the first $2 \mathrm{~d}$ of drought stress for all cultivars. During the 3-11 d of the stress period, however, leaf ABA increased linearly with drought progression for all cultivars (Table 2; Fig. 1). The rate of $\mathrm{ABA}$ accumulation was positively correlated with the rate of turf quality decline under drought stress (Fig. 2). ABA accumulation rate with drought stress ranked as 'RSP' $=$ 'Moonlight' $>=$ 'Brilliant' $=$ 'Baruzo' $=$ 'Alpine' $>$ 'Washington' $=$ 'Midnight' $>=$ 'A82-204'.

Cultivars with higher turf quality had lower ABA content than those with lower turf quality during the $11 \mathrm{~d}$ of stress period (Fig. 1). ABA content in 'Midnight' and 'A82-204' were only $33 \%$ and $56 \%$ of that in 'Moonlight' at $11 \mathrm{~d}$ of drought stress. Volaire et al. (1998) also reported lower ABA content in leaves of a drought-tolerant cultivar compared to that of a drought-susceptible cultivar of perennial cocksfoot (Dactylis glomerata L.). Our results are also consistent with the results of studies on some annual crops, such as maize (Ilahi and Dorffling, 1982), spring wheat (Quarrie, 1980, 1981; Quarrie and Jones, 1979), and sorghum (Durley et al., 1983). ABA accumulation in guard cells during drought induces stomatal closure and prevents excessive water loss at the expense of reduced photosynthesis. Plant survival is a critical factor in the tolerance of perennial grasses, such as kentucky bluegrass, to a prolonged drought. $\mathrm{ABA}$ accumulation is negatively related to photosynthesis due to induced stomatal closure (Aasamaa et al., 2002). Therefore, low accumulation of ABA would be beneficial for the maintenance of photosynthesis during short-term drought, and allow dry matter to accumulate to support plant survival during prolonged drought.

Leaf water potential $(\Psi)$, relative water content (RWC), electrolyte leakage (EL), leaf net photosynthesis $(\mathrm{Pn})$, stomatal conductance $\left(g_{\mathrm{s}}\right)$, 

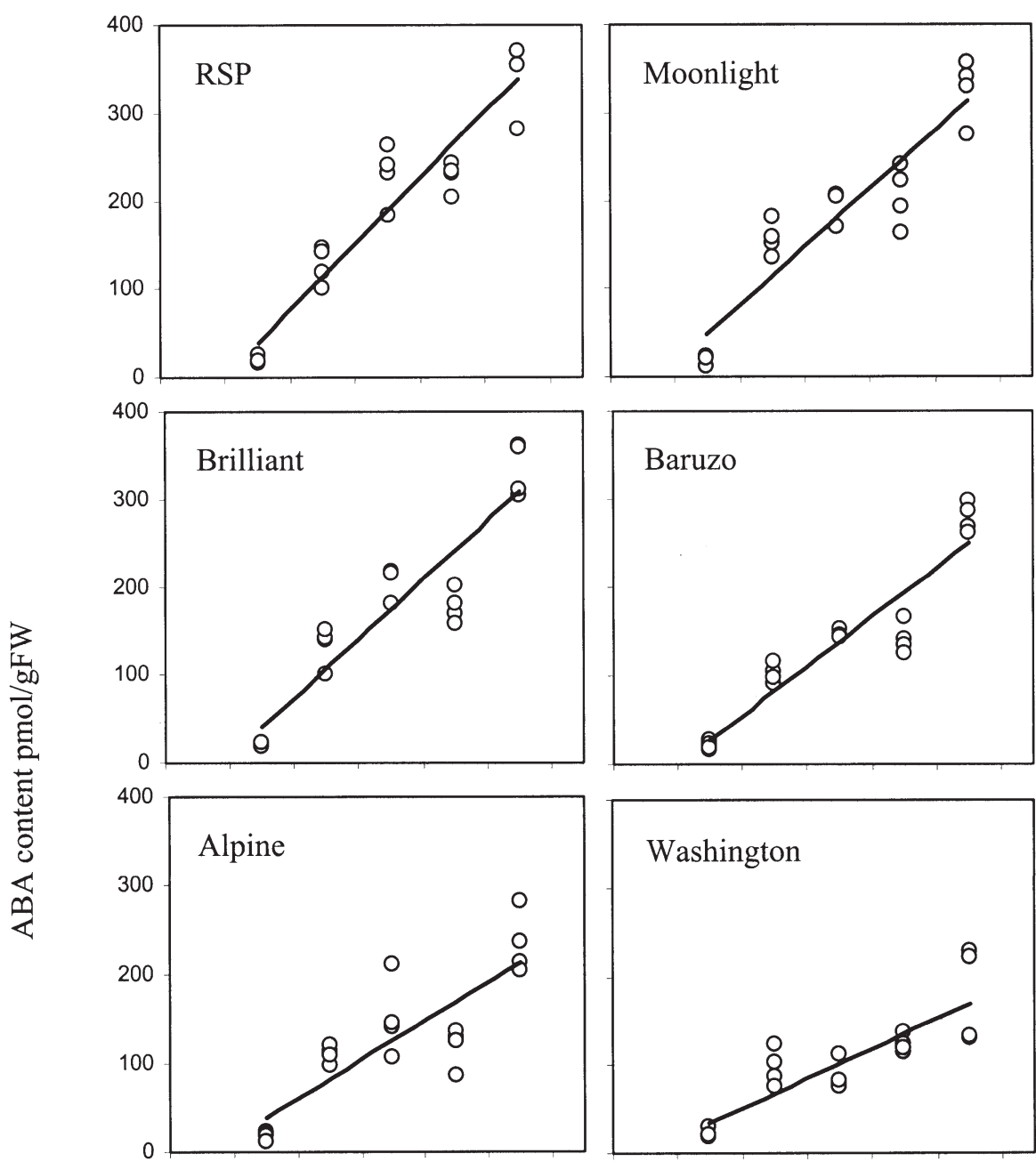

Washington


\section{Days after drought}

Fig. 1. ABA content during the first $11 \mathrm{~d}$ of drought stress in eight kentucky bluegrass cultivars.

and transpiration rate (Tr) have been widely used as physiological indicators to evaluate drought response in turfgrasses (Huang and Fry, 1998; Huang et al., 1998; Lehman et al., 1993; Qian and Fry, 1997). Drought-tolerant cultivars are characterized by a slower decline of $\Psi, \mathrm{RWC}, \mathrm{Pn}, g_{\mathrm{s}}, \mathrm{Tr}$, and increase of EL than drought-susceptible cultivars during prolonged drought stress (Carrow, 1996; Huang and Gao, 1999; Jiang and Huang, 2001; Lehman et al., 1993). Most leaves were completely wilted by $11 \mathrm{~d}$ of drought stress. Photosynthetic rate and stomatal conductance dropped to near zero by $11 \mathrm{~d}$ of drought and photosynthesis became negative after $11 \mathrm{~d}$ of stress for drought-sensitive cultivars (data not shown). Therefore, in this study the relationships between ABA content and physiological parameters were determined using the correlation analysis for data collected within $11 \mathrm{~d}$ of drought stress. Leaf ABA content was negatively correlated with $\Psi$, RWC, $g_{s}, \mathrm{Tr}$, and Pn, but positively related to EL (Fig. 3). The rate of EL increase was an indicator of the rate of cell membrane damage in plants during drought stress, which was positively related to the rate of $\mathrm{ABA}$ accumulation (Fig. 4). The rate of RWC decline was an indicator of the rate of water loss in plants,



Fig. 2. The relationship between the rate of leaf ABA accumulation and rate of turf quality decline during $11 \mathrm{~d}$ of drought for all eight cultivars. Both rates were calculated based on daily changes during drought stress. Correlation coefficients $\left(r^{2}\right)(\mathrm{df}=30)$ were significant at $P=0.01$.

which was also significantly correlated with the rate of ABA accumulation (Fig. 5). ABA is a stress-induced hormone, and its accumulation is largely controlled by leaf water status and depends on the level of stress (Quarrie, 1989; Quarrie and Jones, 1979). In response to drought, plants synthesize ABA, which triggers closing of stomata, thus reducing water loss during the early phase of stress (Schroeder et al., 2001). The rate of ABA accumulation in leaves, therefore, indicates the severity of physiological injuries, which is consistent with other physiological indicators $(\Psi, \mathrm{RWC}$, $g_{s}, \mathrm{Tr}, \mathrm{Pn}$, and EL). In a comparison of ABA accumulation for four cultivars differing in drought tolerance, Wang and Huang (2003) reported that 'Midnight' and 'A82-204', with lower ABA accumulation, maintained higher $\Psi$ and RWC than 'Brilliant' and RSP with higher ABA accumulation under the same level of drought stress.

In summary, kentucky bluegrass cultivars tolerant of drought exhibited slower ABA accumulation rate than drought-sensitive cultivars during short-term drought stress. The accumulation rate of endogenous ABA could be used as a criterion for drought tolerance selection in kentucky bluegrass. Evaluation of endogenous ABA accumulation could greatly improve the efficiency of selection for breeding drought-tolerant turfgrasses, due to the feasibility for the quantification of $\mathrm{ABA}$ for large populations of germplasms.

\section{Literature Cited}

Aasamaa, K., A. Sober, W. Hartung, and U. Niinemets. 2002. Rate of stomatal opening, shoot hydraulic conductance and photosynthetic characteristics in relation to leaf abscisic acid concentration in six temperate deciduous trees. Tree Physiol. 22:267-276.

Alves, A.A.C. and T.L. Setter. 2000. Response of cassava to water deficit: Leaf area growth and abscisic acid. Crop Sci. 40:131-137.

Aronson, L.J., A.J. Gold, and R.J. Hull. 1987. Coolseason turfgrass responses to drought stress. Crop Sci. 27:1261-1266.

Beard, J.B. 1973. Turfgrass: Science and culture. Prentice-Hall, Englewood Cliffs, N.J.

Blum, A. 1989. Breeding methods for drought toler- 

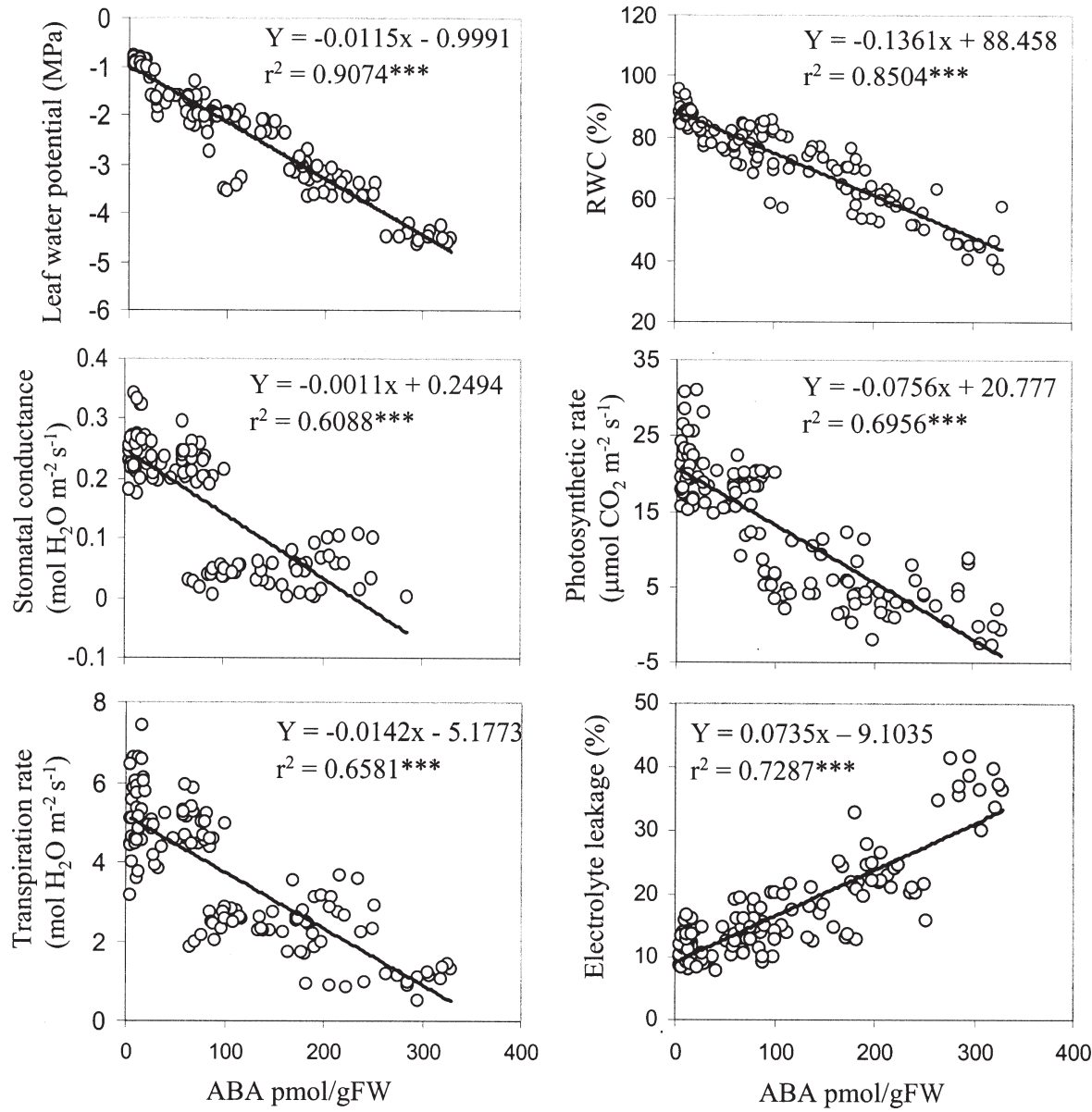

Fig. 3. The relationship between leaf ABA concentration and leaf water potential, relative water content, stomatal conductance, photosynthesis rate, transpiration rate, and electrolyte leakage during $11 \mathrm{~d}$ of drought for all eight cultivars. Correlation coefficients $\left(r^{2}\right)($ d.f. $=126)$ were significant at $p=0.001$.

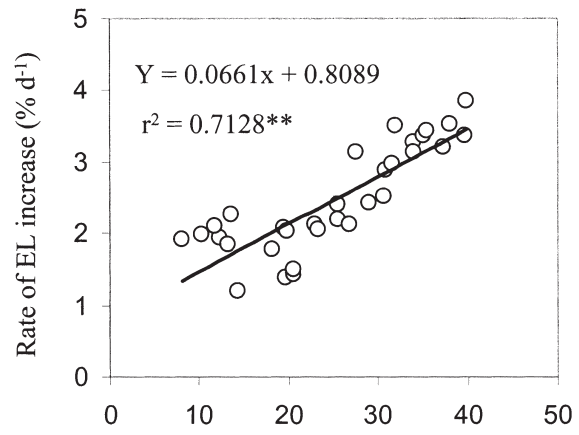

ABA accumulation rate $\left(\mathrm{pmol} \mathrm{g}^{-1} \mathrm{FW} \mathrm{d}^{-1}\right)$

Fig. 4. The relationship between the rate of leaf ABA accumulation and rate of water loss during 11 $\mathrm{d}$ of drought for all eight cultivars. Both rates were calculated based on daily changes during drought stress. Correlation coefficients $\left(r^{2}\right)(\mathrm{df}$ =30) were significant at $P=0.01$.

ance, p. 39-40. Environmental stress in plants: Biochemical and physiological mechanisms. Springer-Verlag, Berlin, Germany.

Bohnert, H.J., D.E. Nelson, and R.G. Jensen. 1995. Adaptations to environmental stresses. Plant Cell 7:1099-1111.

Bonos, S.A. and J.A. Murphy. 1999. Growth responses and performance of kentucky bluegrass under summer stress. Crop Sci. 39:770-774.

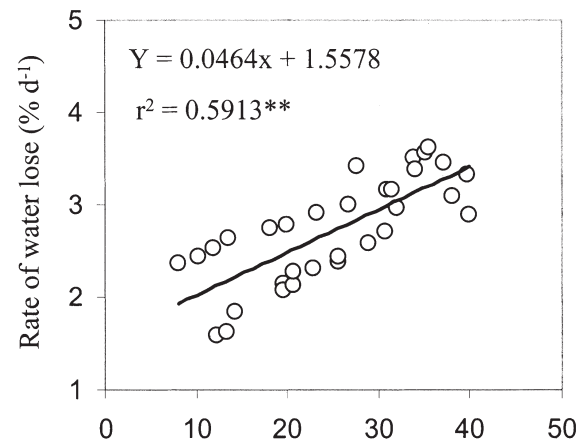

ABA accumulation rate ( $\mathrm{pmol} \mathrm{g}^{-1} \mathrm{FW} \mathrm{d}^{-1}$ )

Fig. 5. The relationship between the rate of leaf ABA accumulation and the rate of electrolyte leakage increase during $11 \mathrm{~d}$ of drought for all eight cultivars. Both rates were calculated based on daily changes during drought stress. Correlation coefficients $\left(r^{2}\right)(\mathrm{df}=30)$ were significant at $P=0.01$.

Bray,E.A. 1993. Molecular responses to water deficit. Plant Physiol. 103:1035-1040.

Cao, W.X., Z.L. Wang, and T.B. Dai. 2000. Changes in levels of endogenous plant hormones during floret development in wheat cultivars of different spike sizes. Acta Bot. Sin. 42:696-700.

Carrow, R.N. 1996. Drought avoidance characteristics of diverse tall fesue cultivars. Crop Sci. 36:371-377.
Conti, S., P. Landi, M.C. Sanguineti, S. Stefanelli, and R. Tuberosa. 1994. Genetic and environmental effects on abscisic acid accumulation in leaves of field-grown maize. Euphytica 78:81-89.

Durley, R.C., T. Kannangara, N. Seetharama, and G.M. Simpson. 1983. Drought tolerance of sorghum bicolor. 5. Genotypic differences in the concentrations of free and conjugated abscisic, phaseic and indole-3-acetic acids in leaves of field-grown drought-stressed plants. Can. J. Plant Sci. 63:131-145.

Huang, B. and J.D. Fry. 1998. Root anatomical, physiological, and morphological responses to drought stress for tall fescue cultivars. Crop Sci. 38:1017-1022.

Huang, B., J.D. Fry, and B. Wang. 1998. Water relations and canopy characteristic of tall fescue cultivars during and after drought stress. HortSci. 33:837-840.

Huang, B. and H. Gao. 1999. Physiological responses of diverse tall fescue cultivars to drought stress. HortSci. 34:897-901.

Ilahi, I. and K. Dorffling. 1982. Changes in abscisic acid and proline levels in maize varieties of different drought tolerance. Physiol. Plant. 55:129-135

Innes, P., R.D. Blackwell, and S.A Qurrie. 1984. Some effects of genetic variation in droughtinduced abscisic acid accumulation on the yield and water use of spring wheat. J. Agr. Sci. 102:341-351.

Jiang, Y. and B. Huang. 2001. Drought and heat stress injury to two cool-season turfgrasses in relation to antioxidant metabolism and lipid peroxidation. Crop Sci. 41:436-442.

Landi, P., M.C. Sanguineti, S. Conti, and R. Tuberosa. 2001. Direct and correlated responses to divergent selection for leaf abscisic acid concentration in two maize populations. Crop Sci. 41:335-344.

Larque-Saavedra, A. and R.L. Wain. 1976. Studies on plant growth-regulating substances. XLII. Abscisic acid as a genetic character related to drought tolerance. Ann. Appl. Biol. 83:291-297.

Lehman, V.G., M.C. Engelke, and R.H. White. 1993. Leaf water potential and relative water content variation in creeping bentgrass clones. Crop Sci. 33:1350-1353.

Ludewig, M., K. Doerffling, and H. Seifert. 1988. Abscisic acid and water transport in sunflowers. Planta 175:325-333.

Pekic, S. and S.A. Quarrie. 1987. Abscisic acid accumulation in lines of maize differing in drought tolerance: a comparion of intact and detached leaves. J. Plant Physiol. 127:203-217.

Pekic, S., R. Stikic, L. Tomljanovic, V. Andjelkovis, M. Ivanovic, and S.A. Quarrie. 1995. Characterization of maize lines differing in leaf abscisic acid content in the field. I. Abscisic acid physiology. Ann. Bot. 75:67-73.

Qian, Y.L. and J.D. Fry. 1997. Water relations and drought tolerance of four turfgrasses. J. Amer. Soc. Hort. Sci. 122:129-133.

Quarrie, S.A. 1980. Genotypic differences in leaf water potential, abscisic acid and proline concentrations in spring wheat during drought stress. Ann. Bot. 46:383-394.

Quarrie, S.A. 1981. Genetic variability and heritability of drought-induced abscisic acid accumulation in spring wheat. Plant Cell Environ. 4:147-151.

Quarrie, S.A. 1989. Abscisic acid as a factor in modifying drought tolerance. Environmental stress in plants: biochemical and physiological mechanism. Springer-verlag, Berlin, Germany. 27-37.

Quarrie, S.A. 1993. Understanding plant responses to stress and breeding for improved stress toler- 
ance-The generation gap. In: T.J. Close and E.A. Bray (eds.). Plant responses to cellular dehydration during enviromental stress. Proc. 16th Ann. Riverside Symp. Plant Physiol., 28-30 Jan. 1993. Current topics in plant physiology. vol. 10. Amer. Soc. Plant Physiol., Rockville, Md.

Quarrie, S.A. and H.G. Jones. 1979. Genotypic variation in leaf water potential, stomatal conductance and abscisic acid concentration in spring wheat subjected to artificial drought stress. Ann. Bot. 44:323-332.

Schroeder, J.I., J.M. Kwak, and G.J. Allen. 2001 Guard cell abscisic acid signaling and engineering drought hardiness in plants. Nature (London) 410:327-330.
Tripathy, J.N., J. Zhang, S. Robin, T.T. Nguyen, and H.T. Nguyen. 2000. QTLs for cell-membrane stability mapped in rice (Oryza sativa L.) under drought stress. Theoret. Appl. Genet. 100:1197-1202.

Tuberosa, R., M.C. Sanquineti, S. Stefanelli, and P. Landi. 1992. Genotypic variation in abscisic acid (ABA) accumulation in artificially water-stressed maize leaves and its relationship with the ABA content in drought-stressed field conditions. J. Genet. Breeding 46:331-334.

Volaire, F., H. Thomas, N. Bertagne, E. Bourgeois, M.F. Gautier, and F. Lelievre. 1998. Survival and recovery of perennial forage grasses under prolonged Mediterranean drought: Water status, solute accumulation, abscisic acid concentration and accumulation of dehydrin transcripts in bases of immature leaves. New Phytol. 140:451-460.

Wang, Z. and B. Huang. 2003. Genotypic variation in abscisic acid accumulation, water relations, and gas exchange for kentucky bluegrass exposed to drought stress. J. Amer. Soc. Hort. Sci. 128:349-355.

Zhang, J., X. Zhang, and J. Liang. 1995. Exudation rate and hydraulic conductivity of maize roots are enhanced by soil drying and abscisic acid treatment. New Phytol. 131:329-336. 